\title{
Simultaneous Monitoring of Presynaptic Transmitter Release and Postsynaptic Receptor Trafficking Reveals an Enhancement of Presynaptic Activity in Metabotropic Glutamate Receptor-Mediated Long-Term Depression
}

\author{
Wei Xu, ${ }^{1 \star}$ Yiu Chung Tse, ${ }^{2 \star}$ Frederick A. Dobie, ${ }^{1}$ Michel Baudry, ${ }^{3}$ Ann Marie Craig, ${ }^{1}$ Tak Pan Wong, ${ }^{2,4}$ \\ and Yu Tian Wang ${ }^{1,5}$ \\ ${ }^{1}$ Brain Research Center, University of British Columbia, Vancouver, British Columbia, Canada V6T 2B5, 2Douglas Mental Health University Institute, \\ Montreal, Quebec, Canada H4H 1R3, ${ }^{3}$ Graduate College of Biomedical Sciences, Western University of Health Sciences, Pomona, California 91766 , \\ ${ }^{4}$ Department of Psychiatry, McGill University, Montreal, Quebec, Canada H4H 1R3, and ${ }^{5}$ Translational Medicine Research Center and Center for \\ Neuropsychiatry, China Medical University Hospital and Graduate Institute of Immunology, China Medical University, Taichung, Taiwan 40447
}

\begin{abstract}
Although the contribution of postsynaptic mechanisms to long-term synaptic plasticity has been studied extensively, understanding the contribution of presynaptic modifications to this process lags behind, primarily because of a lack of techniques with which to directly and quantifiably measure neurotransmitter release from synaptic terminals. Here, we developed a method to measure presynaptic activity through the biotinylation of vesicular transporters in vesicles fused with presynaptic membranes during neurotransmitter release. This method allowed us for the first time to selectively quantify the spontaneous or evoked release of glutamate or GABA at their respective synapses. Using this method to investigate presynaptic changes during the expression of group I metabotropic glutamate receptor (mGluR1/5)-mediated long-term depression (LTD) in cultured rat hippocampal neurons, we discovered that this form of LTD was associated with increased presynaptic release of glutamate, despite reduced miniature EPSCs measured with whole-cell recording. Moreover, we found that specific blockade of AMPA receptor (AMPAR) endocytosis with a membrane-permeable GluR2-derived peptide not only prevented the expression of LTD but also eliminated LTD-associated increase in presynaptic release. Thus, our work not only demonstrates that mGluR1/5-mediated LTD is associated with increased endocytosis of postsynaptic AMPARs but also reveals an unexpected homeostatic/compensatory increase in presynaptic release. In addition, this study indicates that biotinylation of vesicular transporters in live cultured neurons is a valuable tool for studying presynaptic function.
\end{abstract}

\section{Introduction}

Synaptic plasticity, the activity-dependent modification of synaptic strength, is widely thought to underlie information storage and memory formation in the brain. The subcellular localization of the processes underlying synaptic plasticity, presynaptic and/or postsynaptic, has been the subject of intense debate. Recent technological advances in analyzing receptor trafficking

Received March 27, 2012; revised Feb. 16, 2013; accepted Feb. 22, 2013.

Author contributions:W.X.,Y.C.T., F.A.D., M.B., A.M.C., T.P.W., and Y.T.W. designed research;W.X., Y.C.T., F.A.D., T.P.W., and Y.T.W. performed research; W.X., Y.C.T., F.A.D., A.M.C., T.P.W., and Y.T.W. analyzed data; W.X., F.A.D., M.B., T.P.W., and Y.T.W. wrote the paper.

This research was supported in part by grants from Canadian Institutes of Health Research and Howard Hughes Medical Institute, Taiwan Department of Health Clinical Trial and Research Center of Excellence Grant D0H100-TDB-111-004 (Y.T.W.), and Natural Sciences and Engineering Research Council of Canada Discovery Grant 214991 (T.P.W.). We thank YuPing Li, Alice Shui-Ming Wong, and Steven Van Iderstine for technical assistance and Dr. Loren Oschipok for comments and English editing.

The authors declare no competing financial interests.

*W.X. and Y.C.T. contributed equally to this work.

Correspondence should be addressed to Yu Tian Wang, Brain Research Center, University of British Columbia, Vancouver, British Columbia, Canada V6T 2B5. E-mail: ytwang@interchange.ubc.ca.

DOI:10.1523/JNEUROSCI.1508-12.2013

Copyright $\odot 2013$ the authors $\quad 0270-6474 / 13 / 335867-11 \$ 15.00 / 0$ have established that trafficking of glutamate receptors into or away from postsynaptic membranes is a critical mechanism for the expression of various forms of long-term plasticity (Malinow and Malenka, 2002; Collingridge et al., 2004). However, it remains unclear how presynaptic transmitter release changes during synaptic plasticity; this is attributable, at least in part, to the lack of direct and quantitative methods to measure dynamic changes in presynaptic release.

Previously, presynaptic changes were indirectly inferred through the analysis of postsynaptic currents, such as changes in miniature EPSC (mEPSC) frequency, failure rate, and pairedpulse facilitation ratio. However, these measurements can be greatly influenced by postsynaptic changes (Malinow and Malenka, 2002; Moult et al., 2006; Heine et al., 2008). Imaging of synaptic vesicular turnover with an antibody recognizing the lumenal domain of synaptotagmin-1 (Syt1) (Malgaroli et al., 1995) or FM dyes (Zakharenko et al., 2002; Stanton et al., 2003; Zhang et al., 2006) provided valuable direct assessments of presynaptic functions. However, these techniques lack synapse specificity and cannot distinguish changes in release at excitatory terminals from those at inhibitory ones. These imaging approaches were also 
complicated by the existence of different modes of vesicular release (Aravanis et al., 2003) and produced contradictory results (Zakharenko et al., 2002; Zhang et al., 2006). Recently, molecular tools for imaging glutamate release, such as glutamate-sensitive fluorescent reporters, were unsuccessful at detecting synaptic glutamate release (Hires et al., 2008; Looger and Griesbeck, 2012).

Here we designed a biochemical assay measuring the amount of vesicular transporters exposed on the extracellular side of the presynaptic membrane during neurotransmitter release (Voglmaier et al., 2006; Padamsey and Jeans, 2012). Using nonmembrane-permeable biotinylation reagents, we were able to simultaneously label vesicular transporters for glutamate and GABA expressed in glutamatergic and GABAergic synaptic vesicles, respectively (McIntire et al., 1997; Takamori et al., 2000; Fremeau et al., 2001). The unbiased quantification from the entire population of neurons in culture dishes makes this assay less prone to subjectivity or sampling errors seen in imaging studies. Most importantly, this method allows simultaneous labeling of presynaptic vesicle proteins and postsynaptic receptors and thereby provides an opportunity to compare presynaptic and postsynaptic modifications during the expression of synaptic plasticity under the same experimental conditions. With this method, we studied presynaptic and postsynaptic changes in a well characterized form of synaptic plasticity and found an unexpected homeostatic relationship between presynaptic and postsynaptic functions during the expression of this type of plasticity.

\section{Materials and Methods}

Materials. Unless otherwise specified, all reagents were purchased from Sigma. The biotinylation reagents, including Sulfo-NHS-LC-Biotin, Biotin- $\mathrm{PEO}_{4}$-Hydrazide, and Maleimide PEO2-Biotin and NeutraAvidin beads, were purchased from Pierce. The following antibodies were used: VGLUT1 (for Western blotting; catalog \#135 302; Synaptic Systems); VGLUT1 (guinea pig antibody for Syt1 uptake assay; AB5905; Millipore); VGAT (catalog \#131 002; Synaptic Systems); Syt1 (for Western blotting; catalog \#105 011; Synaptic Systems); Syt1 (for Syt1 antibody uptake assay; catalog \#105 103; Synaptic Systems); microtubuleassociated protein 2 (MAP2) (AB5543; Millipore); transferrin receptor (TfR) (catalog \#13-6890; Zymed); $\alpha-1$ subunit of GABA $A_{\mathrm{A}}$ receptor (catalog \#AB5946; Millipore Bioscience Research Reagents), GluA1 (catalog \#AB1504; Millipore Bioscience Research Reagents); and GluA2/3 (cata$\log \# 1506$; Millipore Bioscience Research Reagents). (RS)-3,5Dihydroxyphenylglycine (DHPG) was purchased from Tocris Biosciences.

Hippocampal cultures. Culture dishes and plates and coverslips were coated with $10 \mu \mathrm{g} / \mathrm{ml}$ poly-D-lysine dissolved in Borax buffer $(0.15 \mathrm{M})$, $\mathrm{pH}$ 8.4, overnight. Neurons from E18 rat embryonic hippocampi (from embryos of either sex) were dissociated and plated in Neurobasal medium supplemented with B27 (Invitrogen), $0.5 \mathrm{~mm}$ glutamine, and 12.5 $\mu \mathrm{M}$ glutamate in six-well plates at $0.5 \times 10^{6}$ cells per well or in $10 \mathrm{~cm}$ dishes at $3 \times 10^{6}$ cells per dish. Neurons were switched to maintenance medium (Neurobasal medium supplemented with B27 and $0.5 \mathrm{~mm}$ glutamine) the next day and fed twice per week until they were ready for experiments at $14-18 \mathrm{~d}$ in vitro.

Biotinylation assay. Neurons were first switched from culture medium to normal extracellular solution (ECS) containing the following (in mM): $140 \mathrm{NaCl}, 2.7 \mathrm{KCl}, 1.7 \mathrm{CaCl}_{2}, 1.0 \mathrm{MgCl}_{2}, 10$ HEPES, and 33 glucose. After incubation in ECS at room temperature for 45-60 min, neurons were subjected to various treatments as described in Results. Neurons were then incubated with Sulfo-NHS-LC-Biotin or other biotinylation reagents for the indicated labeling time (5-30 s; $30 \mathrm{~s}$ was used in most assays unless otherwise noted) to allow the vesicular transporters exposed on cell membrane during synaptic release to react with the biotinylation reagents and also to allow released synaptic vesicles to uptake biotinylation reagents. The biotinylation reagents were dissolved in normal ECS for spontaneous release (in this case, neurons were pretreated with $1 \mu \mathrm{M}$ TTX for 5 min before the onset of labeling time), in ECS containing high concentration of potassium (high $\mathrm{K}^{+}$) (in mM: $31.5 \mathrm{NaCl}, 90 \mathrm{KCl}, 1.7$ $\mathrm{CaCl}_{2}, 1.0 \mathrm{MgCl}_{2}, 10 \mathrm{HEPES}$, and 33 glucose) for depolarization-evoked release or in hypertonic ECS with an addition of $500 \mathrm{~mm}$ sucrose (to achieve a total osmolarity of $\sim 810 \mathrm{mOsm}$ ) for measurement of the readily releasable pool. At the end of the labeling time, the biotinylation reagents were removed, and prechilled ECS was poured promptly into the culture dishes or plates to stop synaptic release. After washing three times with prechilled ECS, neurons were incubated in ECS on ice for $30-45 \mathrm{~min}$ and then homogenized in boiling lysis buffer (1\% SDS, 10 $\mathrm{mm}$ Tris, and $0.2 \mathrm{~mm}$ sodium orthovanadate, $\mathrm{pH}$ 7.4). For each well in a six-well plate, $125 \mu \mathrm{l}$ of lysis buffer was used. Cell lysates were shaken on a thermomixer $\left(95^{\circ} \mathrm{C}\right)$ for $5-10 \mathrm{~min}$, sonicated for $30 \mathrm{~s}$, and then centrifuged at 14,000 rpm for $30 \mathrm{~min}$. Supernatants containing equal amounts of total protein were then diluted into RIPA buffer at a 1:10 ratio and incubated with NeutraAvidin beads at $4^{\circ} \mathrm{C}$ overnight to precipitate biotinylated proteins. After washing in RIPA buffer, biotinylated proteins were eluted from the beads by boiling in SDS-Sample buffer. Finally, biotinylated proteins were processed for SDS-PAGE and immunoblotting. Densities of immunoblot bands were digitized and quantified with $\mathrm{NIH}$ ImageJ. All band intensities were normalized to that of control samples.

Syt1 antibody uptake assay. For live staining of actively recycling terminals under control or DHPG treatment conditions, neurons were incubated for $5 \mathrm{~min}$ at $37^{\circ} \mathrm{C}$ in Neurobasal medium supplemented with either $100 \mu \mathrm{m}$ DHPG or an equivalent volume of water, constituting $1 \%$ of the total media volume. Incubation was followed by extensive washing. Neurons were then allowed to recover at $37^{\circ} \mathrm{C}$ for $30 \mathrm{~min}$. After recovery, neurons were incubated at $37^{\circ} \mathrm{C}$ for $30 \mathrm{~min}$ with an antibody to the lumenal domain of Syt1 (rabbit), diluted 1:200 in Neurobasal medium. After extensive washing, neurons were fixed for 12-15 min with warm $4 \%$ formaldehyde and $4 \%$ sucrose in PBS, pH 7.4, followed by permeabilization with PBST (PBS plus $0.25 \%$ Triton X-100). Fixed and permeabilized cultures were blocked in $10 \% \mathrm{BSA}$ in $\mathrm{PBS}$ for $30 \mathrm{~min}$ at $37^{\circ} \mathrm{C}$ and then incubated in primary antibodies against vesicular glutamate transporter 1 (VGLUT1) (guinea pig, 1:2000) and MAP2 (chicken, 1:2000) (diluted in 3\% BSA in PBS) for $2 \mathrm{~h}$ at room temperature. Coverslips were washed with PBS and incubated in secondary antibodies conjugated to Alexa Fluor-568 or 647 dyes or 7-amino-4-methylcoumarin-3-acetic acid, respectively, in $3 \%$ BSA in PBS for $1 \mathrm{~h}$ at $37^{\circ} \mathrm{C}$. The coverslips were then washed and mounted in elvanol [Tris- $\mathrm{HCl}$, glycerol, and polyvinyl alcohol, with $2 \%$ 1,4-diazabicyclo[2,2,2]] octane. The immunocytochemistry images were taken and analyzed with NIH ImageJ. Fluorescent puncta intensity, size, and density were measured by first applying a "Mexican hat" filter (LoG3D; Daniel Sage, Federal Polytechnic School of Lausanne, Lausanne, Switzerland; http://bigwww.epfl.ch/sage/soft/LoG3D/) to aid detection of spots; detected spots were then used as a mask for quantitation.

Peptide treatment. The GluA2 $2_{3 \mathrm{Y}}$ peptide was synthesized according to the following sequence: YKEGYNVYGIE. The transmembrane peptide carrier, pep-1, was synthesized according to a previous report (Morris et al., 2001). GluA2 $2_{3 Y}$ peptide was first mixed with pep-1 at a ratio of $1: 20$ and incubated for $30 \mathrm{~min}$ to let the GluA2 $2_{3 \mathrm{Y}}$-pep-1 complex to form (all peptides were dissolved in ECS). Neurons were pretreated with this peptide complex (at a final concentration of GluA2 $2_{3 Y}$ at $1 \mu \mathrm{M}$ ) for $1 \mathrm{~h}$ to allow the complex to enter neurons.

Electrophysiology. Whole-cell voltage-clamped recordings were made from cultured hippocampal neurons $14-18 \mathrm{~d}$ after plating. The patch electrode solution contained the following (in $\mathrm{mM}$ ): 110 Cs-gluconate, 17.5 CsCl, 0.5 EGTA, $2 \mathrm{MgCl}_{2}$, 10 HEPES, 5 QX314, 0.4 Tris-GTP, and 4 $\mathrm{K}_{2} \mathrm{ATP}, \mathrm{pH} 7.2$ (osmolarity, 290-300 $\mathrm{mOsm}^{-1}$ ). ECS (perfusion or bathing) contained in the following (mM): $140 \mathrm{NaCl}, 1.3 \mathrm{CaCl}_{2}, 5.0 \mathrm{KCl}$, $1.0 \mathrm{MgCl}_{2}, 10$ HEPES, 33 glucose, and 0.001 TTX, pH 7.4 (325-335 $\mathrm{mOsm}^{-1}$ ). Recordings were performed at room temperature. Miniature postsynaptic currents from cultured neurons were recorded using an MultiClamp700B amplifier (Molecular Devices), sampled at $10 \mathrm{kHz}$ after being filtered at $1 \mathrm{kHz}$, and stored in a computer using Clampex 8.0 (Molecular Devices). After $10 \mathrm{~min}$ of stable baseline recording, DHPG was bath applied for $5 \mathrm{~min}$ to induce long-term depression (LTD). mEPSCs 
A

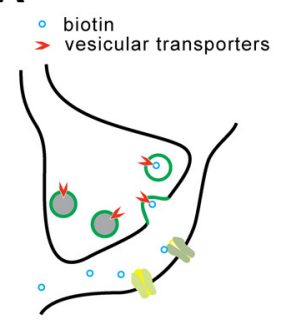

B

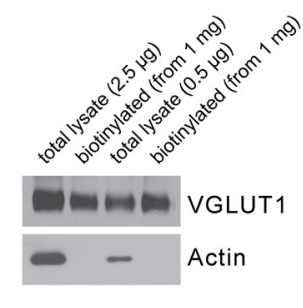

C

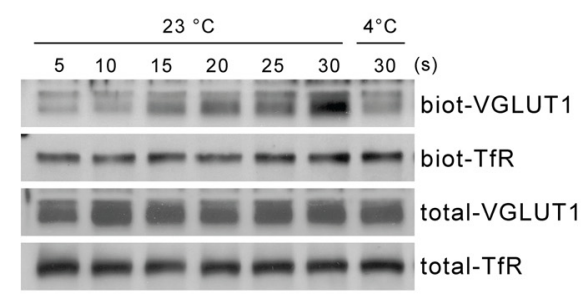

E
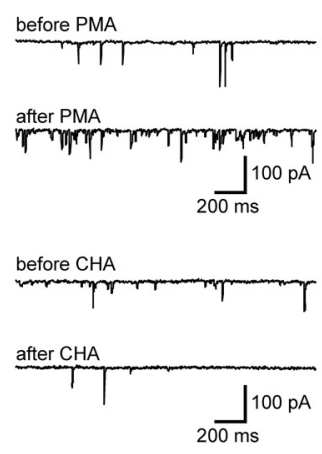

mEPSCs
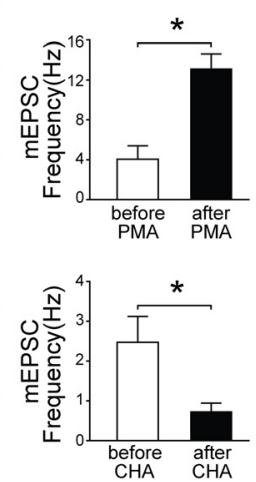

$\mathbf{F}$
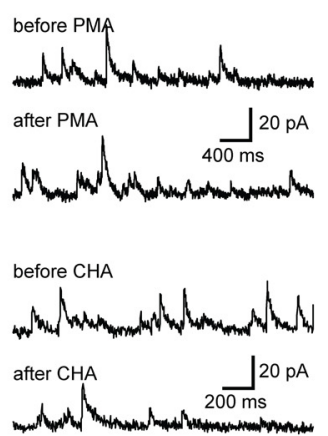

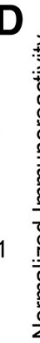

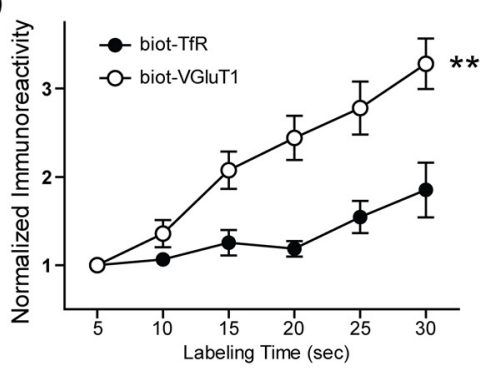

G
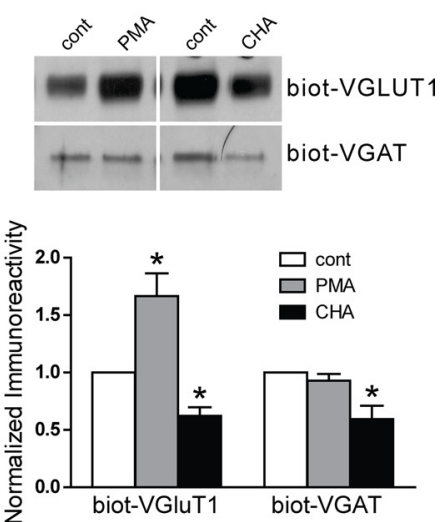

Figure 1. Measurement of spontaneous neurotransmitter release by biotinylation of vesicular transporters. $\boldsymbol{A}$, Schematic diagram showing the biotinylation method. Vesicular transporters are integral membrane proteins of synaptic vesicles and are usually inaccessible to extracellular milieu. However, when vesicles are fused to the plasma membrane during transmitter release, proteins in their intraluminal domains become exposed to the outside of the plasma membrane surface and can be biotinylated by membrane-impermeant reagents added in the ECS. Biotinylated transporters can then be affinity purified and quantified with immunoblots. $\boldsymbol{B}$, Biotinylation of transporters distributed on the cell surface. Cultured neurons were incubated with biotinylation reagents at room temperature for $30 \mathrm{~s}$. Both total cell lysate and isolated biotinylated proteins were loaded onto the same gel and blotted for VGLUT1 and $\beta$-actin, respectively. The representative blot showed that only the surface-localized VGLUT1 but not the cytosolic protein $\beta$-actin was labeled by biotin. In addition, the result indicated that biotinylated VGLUT1 represented only a small fraction of total VGLUT1, because levels of biotinylated VGLUT1 precipitated from $1 \mathrm{mg}$ of total protein were comparable with total VGLUT1 level in $0.5-2.5 \mu \mathrm{g}$ of total proteins. This is consistent with the observation that only a small fraction of synaptic vesicles is recycling at a given time. C, D, VGLUT1 biotinylation reliably detects time-dependent increase in non-action-potential-driven spontaneous presynaptic glutamate release. Representative blots $(\boldsymbol{C})$ and quantification from four separate experiments $(\boldsymbol{D})$ showing that, with increased labeling time (duration of incubation with biotinylation reagents), VGLUT1 biotinylation (biot-VGLUT1) increases at a significantly faster rate than that of the control membrane protein TfR (biot-TfR) (** $<<0.001$, two-way ANOVA). Cultured neurons were pretreated with $1 \mu \mathrm{m}$ of TTX for $5 \mathrm{~min}$ (TTX was used in all experiments involving spontaneous release in this figure and thereafter) and then switched to an ECS containing the biotinylation reagent Sulfo-NHS-LC-Biotin for the indicated periods of labeling time at room temperature or at $4^{\circ} \mathrm{C}$. $\boldsymbol{E}, \boldsymbol{F}$, Electrophysiology recording of spontaneous tetrodotoxin-insensitive mEPSCs or mIPSC in cultured neurons. The PKC activating phorbol ester PMA increased the frequency of mEPSC $(p<0.05$, Student's t test, $n=6)$ only, whereas the adenosine $1 \alpha$ receptor agonist CHA decreased both mEPSC ( $p<0.05$, Student's $t$ test, $n=6)$ and mIPSC ( $p<0.05$, Student's $t$ test, $n=7)$. $\mathbf{G}$, Vesicular biotinylation simultaneously detects differential modulations in presynaptic glutamate and GABA release. Representative blots and bar graph of quantification showing the selective increase in VGLUT1 biotinylation (biot-VGLUT1) by PMA and the nonselective decrease in both VGLUT1 biotinylation (biot-VGLUT1) and VGAT biotinylation (biot-VGAT) by CHA ( ${ }^{*} p<0.05$, Student's $t$ test, $\left.n=4\right)$. Neurons were treated with PMA (1 $\mu \mathrm{m}$ ) or CHA (10 $\mu \mathrm{m}$ ) for 10 min and then switched to ECS containing Sulfo-NHS-LC-Biotin for a 30 s labeling period at room temperature.

and mIPSCs were recorded while voltage clamping the recorded neurons at -60 and $0 \mathrm{mV}$, respectively. In addition, mEPSCs and mIPSCs were, respectively, isolated using inhibitors for $\mathrm{GABA}_{\mathrm{A}}$ receptors $(10 \mu \mathrm{M}$ bicuculline methiodide) and AMPA receptors (AMPARs) $[20 \mu \mathrm{M}$ 6,7-dinitroquinoxaline-2,3(1H,4H)-dione].

Statistics. Data were shown as mean \pm SEM. Student's $t$ tests were used for statistical comparison between two groups. One-way ANOVA was used for comparisons between more than two groups. For imaging data obtained in Syt1 antibody uptake assays, the cumulative probability distribution of each of three independent experiments ( 20 cells each) was determined using equal bin sizes for all data to account for variability in the number of observations. These distributions were then averaged to obtain the mean cumulative probability distribution for all experiments $(n=3)$. Distributions were compared using the Kolmogorov-Smirnov test.

\section{Results}

Measurement of non-action potential-driven spontaneous release by biotinylation of vesicular transporters

Vesicular transporters are transmembrane proteins specifically located in vesicles within the presynaptic terminals and are therefore separated from the extracellular matrix by the presynaptic membrane (Fig. 1A). However, during either spontaneous or evoked transmitter release, synaptic vesicles fuse with the presynaptic plasma membrane and hence the lumenal domains of these transporter proteins are exposed to the extracellular medium, making them accessible to membrane-impermeable biotinylating reagents added to the extracellular medium. The vesicular transporters are specific for the type of synapses using the corresponding neurotransmitter (McIntire et al., 1997; Takamori et al., 2000), and therefore their biotinylation allows selective monitoring of the release of specific neurotransmitters. To date, three VGLUTs have been identified, and, among them, VGLUT1 and VGLUT2 are complementarily expressed by two different populations of excitatory neurons (Fremeau et al., 2001). In this study, we chose VGLUT1 because of its predominance in glutamatergic hippocampal neurons (Fremeau et al., 2001). We also chose vesicular GABA transporter (VGAT) for GABAergic terminals (McIntire et al., 1997). We first tested whether biotinylation could be used to monitor non-action potential-driven spontaneous release of synaptic vesicles. Hippocampal neuronal cultures were incubated in ECS supplemented with TTX for 5 min to block voltage-gated sodium channels and hence the generation of action potentials (this procedure was used in all experiments in- 
volving spontaneous neurotransmitter release). Cultures were then switched into ECS containing a biotinylating reagent (SulfoNHS-LC-Biotin, $1 \mathrm{mg} / \mathrm{ml}$ ) for different durations (5-30 s) at room temperature. After this short labeling time, Sulfo-NHSLC-Biotin was washed away with prechilled ECS to stop additional membrane trafficking. Labeling of vesicular transporters occurs immediately when synaptic vesicles are released and exposed to the extracellular medium. Biotinylation reagent could also be trapped by recycled vesicles and biotinylation reaction could continue inside vesicles (Fig. $1 A$ ). After the biotinylation reagent was washed away from the ECS, cells were kept in cold ECS for $30 \mathrm{~min}$ to allow the incorporated biotinylation reagent to react completely with vesicle-associated proteins. Neurons were then lysed, and biotin-tagged proteins were affinity precipitated with avidin beads and analyzed with SDS-PAGE and immunoblotting. As shown in Figure $1 B$, VGLUT1 but not the cytosolic protein $\beta$-actin was labeled by the surface biotinylation reaction. In addition, only a small fraction of VGLUT1 was biotinylated compared with the total expression level of this protein in neurons, consistent with the observation that only a small fraction of synaptic vesicles are undergoing recycling at any given time. The amount of biotin-tagged VGLUT1 increased in proportion to the length of labeling time between 5 and $30 \mathrm{~s}$ (Fig. 1C,D). By $30 \mathrm{~s}$, we observed an average of $3.28 \pm 0.29$-fold increase in the amount of biotin-tagged VGLUT1 $(n=4)$. As a control, we measured the biotinylation of TfR during the same period of time from the same samples. TfR is a dendritic protein (Silverman et al., 2001) whose surface expression is not directly affected by presynaptic release. Although the amount of TfR biotinylation also increased with labeling time (Fig. 1C,D), its level of increase was significantly lower than that of VGLUT1 (Fig. $1 D ; F_{(1,30)}=18.7, p<$ 0.01, two-way ANOVA comparing TfR and VGLUT1; $n=4)$. This small increase in TfR labeling may reflect the fact that the biotinylation reaction with surface proteins could not be completed within this amount of time and that increasing the reaction time could allow more proteins to be labeled. The higher level of increase in VGLUT1 biotinylation, compared with that of TfR, could be attributed to the accumulation of spontaneous release events during the labeling time, which increased the amount of transporters accessible to the biotinylation reagent. As additional confirmation of this idea, we conducted the biotinylation at $4^{\circ} \mathrm{C}$, a temperature at which active vesicular release is stopped. Under this condition, VGLUT1, but not TfR, biotinylation drastically decreased compared with that at room temperature (Fig. $1 C$ ). The results indicate that biotinylation with membraneimpermeable reagents can be used to monitor spontaneous turnover of synaptic vesicles.

Next we tested whether biotinylation of transporters was sensitive enough to detect drug-induced changes in spontaneous neurotransmitter release (Fig. $1 E-G$ ). We treated neurons with phorbol 12-myristate 13-acetate (PMA) (1 $\mu \mathrm{M}, 10 \mathrm{~min}$ ), a phorbol ester known to increase glutamate release (Lonart and Südhof, 2000; Rhee et al., 2002). As shown in Figure 1, E and F, PMA selectively increased the frequency of mEPSC but not that of mIPSC. Consistent with this observation, PMA treatment increased biotinylation of VGLUT1 with a labeling time of $30 \mathrm{~s}$ to $1.67 \pm 0.20$-fold of control (Fig. $1 G$; $t$ test, $p<0.05, n=4$ ), without significantly altering the level of VGAT biotinylation $(0.93 \pm 0.06$-fold of control, $t$ test, $p>0.05, n=4)$, consistent with a specific upregulation of neurotransmitter release in glutamatergic, but not GABAergic, presynaptic terminals.

We also treated cells with N6-cyclohexyladenosine (CHA; 10 $\mu \mathrm{M})$ for $10 \mathrm{~min}$, an adenosine $\mathrm{A}_{1}$ receptor agonist that has been reported to reduce presynaptic release (Manzoni et al., 1994; Jeong et al., 2003). As expected, this treatment significantly reduced the frequency of both mEPSC and mIPSC (Fig. 1E,F). Accordingly, CHA decreased the levels of biotinylation of both VGLUT1 $(0.62 \pm 0.08$-fold of control, $t$ test, $p<0.05, n=4)$ and VGAT $(0.59 \pm 0.12$-fold of control, $t$ test, $p<0.05, n=4$; Fig. $1 G)$. Together, these results indicate that non-action potentialdriven vesicular release of glutamate and GABA can be selectively monitored by biotinylation of VGLUT1 and VGAT, respectively, with cell-impermeable labeling reagents.

\section{Measurement of evoked release by biotinylation of vesicular transporters}

We then tested whether transporter biotinylation could be used to monitor evoked neurotransmitter release. Spontaneous release occurs with low frequency in cultured neurons (Murthy and Stevens, 1999), whereas neuronal depolarization elicits synchronized vesicular release events and therefore increases the number of vesicular transporters accessible to biotinylation reagent. We first used ECS containing high $\mathrm{K}^{+}$(containing $90 \mathrm{~mm}$ potassium) to depolarize neurons (Fig. $2 A$ ). Neurons were incubated with biotinylation reagent (Sulfo-NHS-LC-Biotin, $1 \mathrm{mg} / \mathrm{ml}$ ) diluted in normal ECS or ECS containing high $\mathrm{K}^{+}$for $30 \mathrm{~s}$ to monitor spontaneous and evoked release, respectively. Compared with the control group, the high $\mathrm{K}^{+}$group displayed higher level of biotinylation of VGLUT1 but not that of other membrane proteins, such as TfR and GluA2/3, indicating that the increase is attributable to enhanced vesicular release. Omission of calcium from the high $\mathrm{K}^{+}$medium significantly curbed the increase in VGLUT1 biotinylation, indicating that depolarization-induced release is calcium dependent. The incomplete effect of eliminating calcium in the medium on high $\mathrm{K}^{+}$-elicited increased labeling is probably attributable to the presence of some residual calcium left during the switch of solutions. Pretreating neurons with TTX (1 $\mu \mathrm{M}, 5 \mathrm{~min})$ only slightly reduced the increase of VGLUT1 biotinylation induced by high $\mathrm{K}^{+}$, indicating that a direct depolarization of synaptic terminals with high $\mathrm{K}^{+}$may be sufficient to induce this type of evoked release in the absence of action potential.

Sulfo-NHS-LC-Biotin labels proteins by reacting with their primary amine groups. However, neurotransmitters such as glutamate or GABA also contain primary amines and may compete with proteins for biotinylation and hence reduce labeling efficiency. To optimize the biotinylation method, we tested two other types of biotinylating reagents, including Maleimide PEO2Biotin, which reacts with sulfhydryl groups, and Biotin- $\mathrm{PEO}_{4}$ Hydrazide, with carbohydrate. VGLUT1 contains two cysteine residues and a putative glycosylation site in its putative lumenal domains (Fremeau et al., 2001) and therefore may be able to react with both reagents. These biotinylation reagents were diluted in normal ECS (for spontaneous release) or in high $\mathrm{K}^{+}$ECS (for evoked release) at a concentration of $1 \mathrm{mg} / \mathrm{ml}$. Labeling time was $30 \mathrm{~s}$ for all three reagents. Compared with Sulfo-NHS-LC-Biotin (-NH2) (Fig. 2B), Maleimide PEO2-Biotin (-SH) showed similar efficiency in labeling spontaneous release as indicated by the generation of similar level of biotin-labeled VGLUT1, but was less efficient in tagging TfR and GluA2/3. Biotin- $\mathrm{PEO}_{4}-\mathrm{Hydrazide}$ $(=\mathrm{CO})$ did not generate detectable signal, possibly because of the presence of glucose in the ECS that quenched the reagent or the requirement of oxidization to generate carbonyls for the biotinylation reaction. When biotinylation was conducted in high $\mathrm{K}^{+}$, Maleimide PEO2-Biotin generated signals stronger than that of Sulfo-NHS-LC-Biotin, suggesting that the massive release of glu- 
A
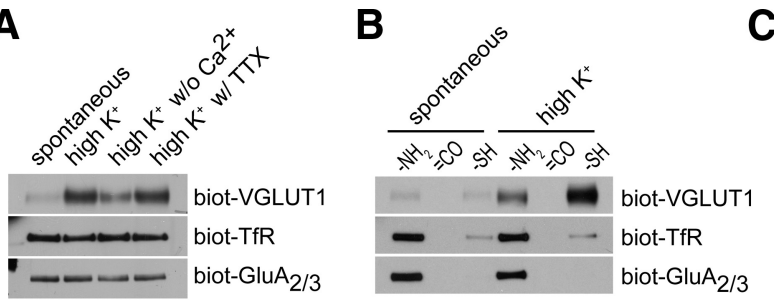
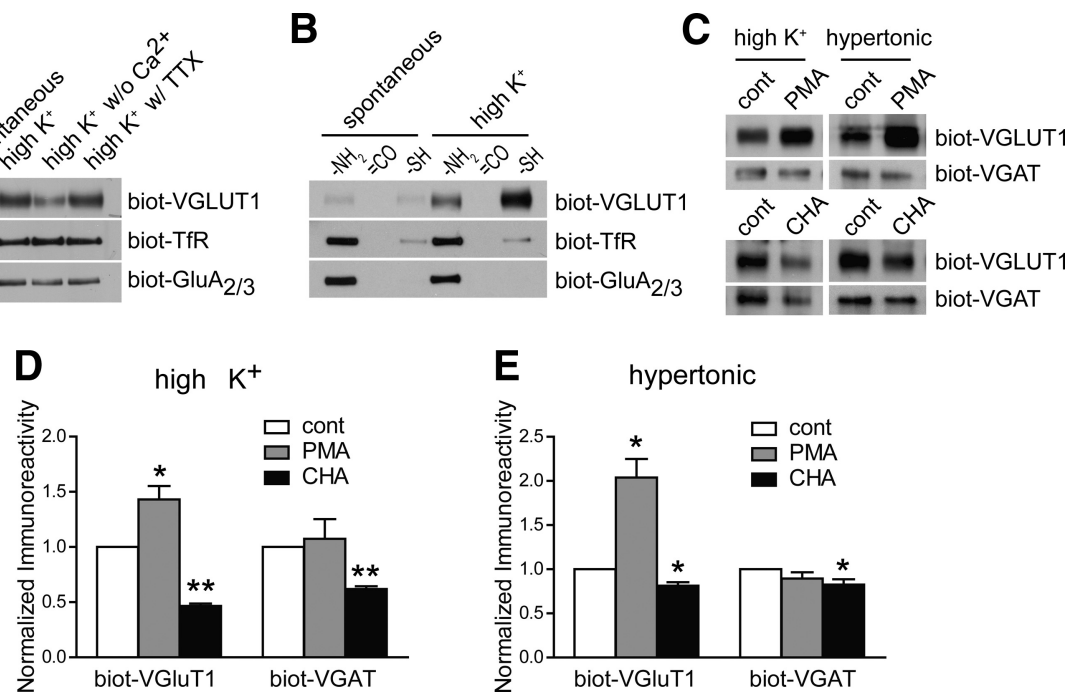

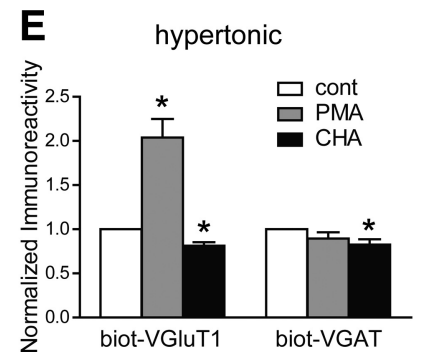

Figure 2. Detection of evoked neurotransmitter release by vesicular transporter biotinylation. $\boldsymbol{A}$, Western blots showing that VGLUT1 biotinylation can reliably detect depolarization-evoked increase in presynaptic glutamate release. Neurons were labeled with Sulfo-NHS-LC-Biotin in normal ECS (spontaneous) and ECS containing $90 \mathrm{~mm}$ of potassium (high $\mathrm{K}^{+}$), respectively. Such a transient high $\mathrm{K}^{+}$treatment significantly increases VGLUT1 biotinylation (biot-VGLUT1) but not TfR biotinylation (biot-TfR) or postsynaptic AMPAR biotinylation (biot-GluA2/3). This effect was reduced by omitting calcium from the ECS (high $\mathrm{K}^{+} \mathrm{w} / 0 \mathrm{Ca}^{2+}$ ) but not by the pretreatment with $1 \mu \mathrm{m}$ of TTX for $5 \mathrm{~min}$ (high $\mathrm{K}^{+} \mathrm{W} / \mathrm{TTX}$ ). $\boldsymbol{B}$, Vesicular transporter biotinylation efficiency varies among different biotinylation reagents. The same concentration $(1 \mathrm{mg} / \mathrm{ml})$ of Sulfo-NHS-LC-Biotin (-NH2, reacting with primary amines), Biotin- $\mathrm{PEO}_{4}$-Hydrazide (=CO, reacting with carbohydrate), and Maleimide PEO2-Biotin (-SH, reacting with sulfhydryl groups) were used to label spontaneous release or high $\mathrm{K}^{+}$-evoked release. Sulfo-NHS-LC-Biotin appears efficient to label vesicular transporters under both spontaneous and evoked conditions, as well as other membrane proteins such as TfR and GluA2/3. Conversely, Maleimide PE02-Biotin is more efficient in labeling VGLUT1 only under evoked release and is also less efficient in labeling TfR and GluA2/3. C-E, VGLUT1 biotinylation reliably measures both facilitating and inhibiting modulation of evoked presynaptic glutamate release. Representative blots $(\boldsymbol{C})$ and quantification from individual cultures stimulated with high $\mathrm{K}^{+}(\boldsymbol{D})$ or hypertonic solution $(\boldsymbol{E})$, showing that, under both high $\mathrm{K}^{+}$and hypertonic conditions, PMA only increases VGLUT1 biotinylation (biot-VGLUT1) but not VGAT biotinylation (biot-VGAT), whereas CHA decreases both VGLUT1 and VGAT biotinylation $\left({ }^{*} p<0.05\right.$, ${ }^{* *} p<0.001$, Student's $t$ test, $n=4-6$ ). Neurons were treated with PMA or CHA and then switched to Sulfo-NHS-LC-Biotin diluted in ECS containing $90 \mathrm{~mm}$ of potassium (high $\mathrm{K}^{+}$) or in ECS containing $0.5 \mathrm{~m}$ sucrose (hypertonic) for $30 \mathrm{~s}$ at room temperature. cont, Control.

tamate in this situation reduced the efficiency of the latter reagent. Together, these data indicate that the biotinylation reagents targeting the $-\mathrm{SH}$ groups are best suited for measuring presynaptic release, whereas reagents targeting - $\mathrm{NH} 2$ groups provide additional information by simultaneously labeling other presynaptic and postsynaptic membrane proteins.

We further tested whether the biotinylation method can sensitively and reliably detect modifications of evoked release. Neurons were treated with PMA $(1 \mu \mathrm{M}, 10 \mathrm{~min})$ or $\mathrm{CHA}(10 \mu \mathrm{M}, 10$ $\mathrm{min})$, respectively, and synaptic release was elicited by incubating neurons for $30 \mathrm{~s}$ in high $\mathrm{K}^{+}$supplemented with Sulfo-NHS-LCBiotin (Fig. 2C,D). PMA increased VGLUT1 biotinylation by $1.43 \pm 0.12$-fold ( $t$ test, $p<0.05, n=4$ ), although it had no effect on VGAT biotinylation ( $1.07 \pm 0.18$-fold of control; $t$ test, $p>$ $0.05, n=4)$. Treatment with CHA resulted in a significant decrease in both glutamatergic $(0.47 \pm 0.02$-fold of control, $t$ test, $p<0.001, n=4)$ and GABAergic (0.62 \pm 0.02 -fold of control, $t$ test, $p<0.001, n=4)$ vesicles. We also used hypertonic ECS (containing $500 \mathrm{~mm}$ sucrose, $810 \mathrm{mOsm}$ total osmolarity) to elicit presynaptic release because hypertonic sucrose solution selectively depletes the readily releasable pool of synaptic vesicles (Rosenmund and Stevens, 1996). As shown in Figure 2, $C$ and $E$, PMA (1 $\mu \mathrm{M}, 10 \mathrm{~min})$ also selectively and significantly increased sucrose-evoked release at glutamatergic terminals as assessed by increased level of VGLUT1 biotinylation (Fig. 2E; $2.04 \pm 0.21$ fold of control, $t$ test, $p<0.05, n=4$ ), without altering that of
VGAT biotinylation (Fig. 2E; $0.89 \pm 0.07-$ fold of control, $t$ test, $p>0.05, n=5$ ). Consistent with the nonselective inhibition of presynaptic release at both glutamatergic and GABAergic terminals, treatment with $\mathrm{CHA}(10 \mu \mathrm{M}, 10 \mathrm{~min})$ significantly reduced the hypertonic ECSinduced labeling of both VGLUT1 $(0.81 \pm 0.04$-fold of control, $t$ test, $p<$ $0.05, n=4)$ and VGAT $(0.83 \pm 0.06$-fold of control, $t$ test, $p<0.05, n=6)$. These results suggest that evoked vesicular release and the readily releasable pool can also be estimated by the biotinylation assay.

\section{DHPG treatment induces long-term facilitation of presynaptic release} Having established this biotinylation assay, we applied it to examine presynaptic release in a synaptic plasticity model. We followed well-established protocols to induce LTD in hippocampal neuronal cultures using a group I mGluR agonist, DHPG (Snyder et al., 2001; Xiao et al., 2001; Waung et al., 2008). We first confirmed the efficacy of DHPG to induce LTD of AMPAR-mediated synaptic transmission using whole-cell recordings of mEPSCs in the presence of TTX $(1 \mu \mathrm{M})$ throughout the recording period. As shown in Figure 3, bath application of DHPG $(100 \mu \mathrm{M})$ for $5 \mathrm{~min}$ produced a long-lasting and significant reduction of mEPSCs, which was primarily manifested as a reduction in mEPSC frequency (Fig. $3 A-C)$, without significantly altering the amplitude or kinetics of mEPSCs. Consistent with the previously reported AMPAR endocytosis in mGluR-LTD (Snyder EM et al., 2001; Xiao MY et al., 2001; Waung MW et al., 2008), we found that intracellular application of the well-characterized AMPAR endocytosis inhibitor GluA2 $2_{3 Y}$ into the postsynaptic neurons by including it in the recording pipette eliminated DHPGinduced reduction of mEPSC frequency (Fig. $3 D-F$ ). These results are in full agreement with previous results indicating that mGluR-LTD is primarily expressed postsynaptically and that reduced mEPSC frequency is likely a result of reduced number of postsynaptic AMPARs (Snyder et al., 2001; Xiao et al., 2001; Huang et al., 2004; Hsieh et al., 2006; Moult et al., 2006).

Although LTD expression is associated with increased endocytosis of postsynaptic receptors, the reduced frequency of mEPSCs suggested that there may also be an associated reduction in presynaptic release during LTD expression. We therefore investigated potential alteration in presynaptic release during mGluR-LTD using the biotinylation-based measurement of presynaptic release. Neurons were treated with DHPG $(100 \mu \mathrm{M})$ for 5 min, and DHPG was washed away with ECS. After incubation in DHPG-free ECS for another $45 \mathrm{~min}$, neurons were switched to ECS containing Sulfo-NHS-LC-Biotin for 5-20 s. Surprisingly, DHPG-treated neurons exhibited an increase in the level of VGLUT1 (but not VGAT or TfR) biotinylation (Fig. 4A). We therefore further assayed presynaptic release by determining the level of biotinylation of another synaptic vesicle-associated pro- 
A

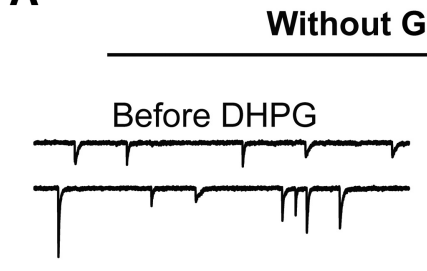

B

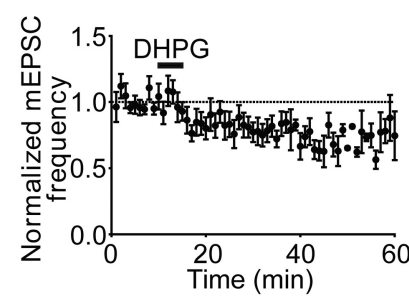

C

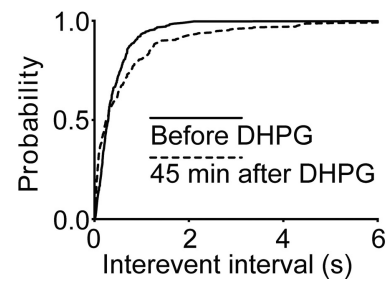

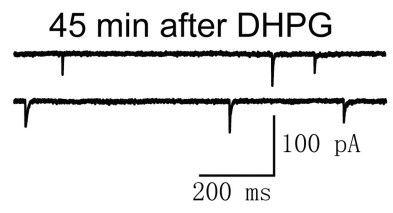
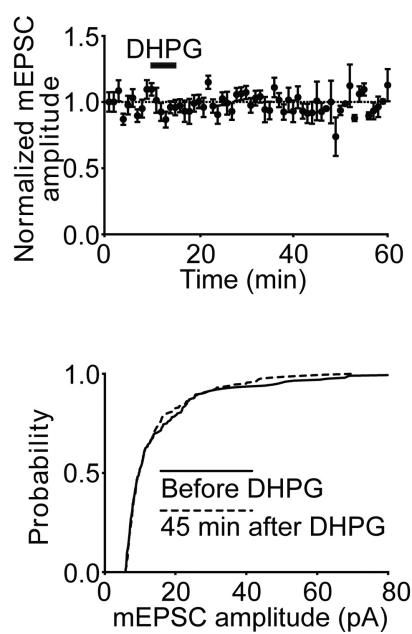

D

Pre-loaded with GluA2

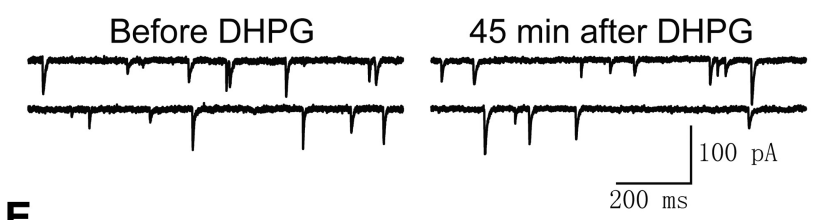

E
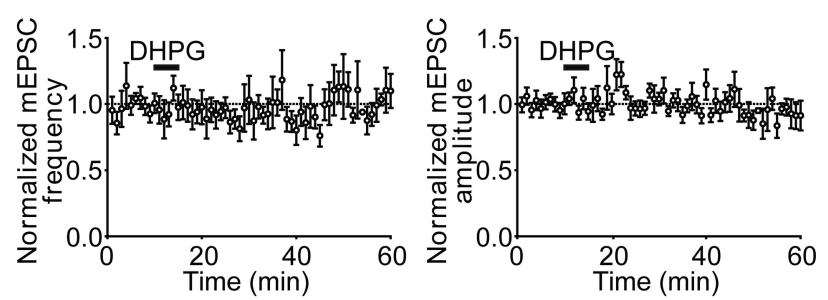

F

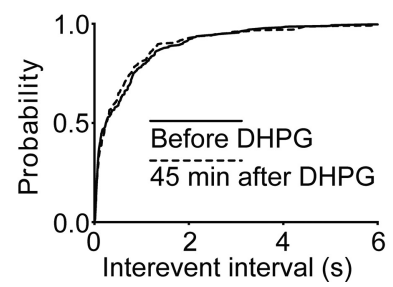

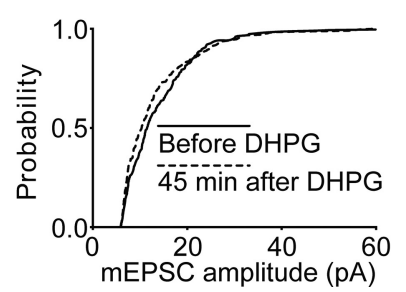

Figure 3. DHPG treatment produces mGluR-mediated LTD of mEPSCs via a mechanism involving facilitation of postsynaptic AMPAR endocytosis in cultured hippocampal neurons. $\boldsymbol{A}-\boldsymbol{C}$, DHPG treatment (100 $\mu \mathrm{m}$ for $5 \mathrm{~min}$ ) produces a long-lasting reduction in $\mathrm{mEPSCs}$. Raw traces $(\boldsymbol{A})$ show representative traces of whole-cell $\mathrm{mEPSC}$ recordings at a holding voltage of $-60 \mathrm{mV}$, taken at 5 min before and $45 \mathrm{~min}$ after DHPG application. $\boldsymbol{B}$, The normalized frequency and amplitude of mEPSCs before and after the application of DHPG. DHPG produced a long-term decrease in mEPSC frequency ( $p<0.05$, Student's $t$ test, $n=9$ ) but not in mEPSC amplitude. C, Cumulative plots of interevent intervals constructed from consecutive synaptic events recorded at 5 min before and 45 min after DHPG application ( $n=9$ ) show DHPG-induced decrease in mEPSC frequency, as indicated by the right shift of the cumulative plot of interevent intervals. $\boldsymbol{D}-\boldsymbol{F}$, In the presence of $G$ luA2 $3 Y$ peptide, the effects of DHPG treatment on mEPSC were abolished ( $p>0.05$, Student's $t$ test, $n=9$ ). Raw traces $(\boldsymbol{D})$ show representative traces of mEPSC recorded from a GluA2 $2_{3 \gamma}$ peptide treated neuron at $5 \mathrm{~min}$ before and $45 \mathrm{~min}$ after DHPG application. $\boldsymbol{E}, \boldsymbol{F}$, The normalized frequency and amplitude of mEPSCs before and after the application of DHPG $(\boldsymbol{E})$ and the cumulative distribution $(\boldsymbol{F})$ of $m E P S C$ were plotted in the same way as those in $\boldsymbol{A}-\boldsymbol{C}$. Note that DHPG failed to alter the frequency and amplitude of $m E P S C s$ in $G$ luA2 ${ }_{3 Y}$ Peptide-treated neurons.

tein, Syt1, using the same immunoblotting membranes. Similar to VGLUT1, the level of Syt 1 biotinylation was also increased by DHPG (Fig. 4A). Although, Syt 1 cannot distinguish glutamatergic terminals from GABAergic terminals such as VGLUT1, given that there are many more glutamatergic ( $~ 80 \%$ of total synapses; Ma et al., 1999) than GABAergic synapses in cultured hippocampal neurons, the increase in Syt1 biotinylation indicated increased synaptic release. To determine whether DHPG enhances both spontaneous and evoked release, we performed another set of experiments in which neurons were incubated with ECS containing Sulfo-NHS-LC-Biotin in the absence (for spontaneous release) or presence (for evoked release) of high $\mathrm{K}^{+}$for $30 \mathrm{~s} 45$ min after DHPG treatment. As shown in Figure $4, B$ and $C$, DHPG increased both spontaneous and evoked release by $1.72 \pm$ 0.23 -fold $(p<0.05, t$ test, $n=5)$ and $1.56 \pm 0.03$-fold $(p<$ $0.001, t$ test, $n=5$ ) compared with their respective controls. Together, these results indicate that DHPG treatment selectively increases presynaptic release at glutamatergic synapses in hippocampal neuronal cultures. We also monitored spontaneous presynaptic release at multiple time points after DHPG application. The results indicate that the release rapidly increased after DHPG treatment (Fig. 4D,E).

Next we tested whether DHPG treatment facilitates presynaptic function through the augmentation of the readily releasable pool, as suggested by a previous study in synaptosomes (Lonart and Südhof, 2000). Neurons were treated with DHPG for $5 \mathrm{~min}$, and after incubation in DHPG-free ECS for an additional 30 or 60 min, neurons were switched to sucrose-based hypertonic ECS containing Sulfo-NHS-LC-Biotin for $30 \mathrm{~s}$. As shown in Figure 4, $F$ and $G$, we observed an increase in biotinylation level of both VGLUT1 ( $1.68 \pm 0.16$-fold of control at $30 \mathrm{~min}, p<0.05$, $t$ test; $1.67 \pm 0.07$-fold of control at $60 \mathrm{~min}, p<0.01$, $t$ test, $n=4$ for each of the three groups) and Syt 1 ( $1.45 \pm 0.13$-fold of control at $30 \mathrm{~min}, p<0.05$, $t$ test; $1.62 \pm 0.17$-fold of control at $60 \mathrm{~min}, t$ test, $p<0.05, n=4$ for each of the three groups) but no change in that of VGAT $(0.94 \pm 0.16$-fold of control at $30 \mathrm{~min}, p>0.05$, $t$ test; $1.02 \pm 0.08$-fold of control at $60 \mathrm{~min}, p>0.05$, $t$ test, $n=$ 4 for each of the three groups). These results strongly suggest that DHPG selectively and persistently increases presynaptic release through an augmentation of the readily releasable pool at excitatory synapses during the expression of mGluR-LTD.

To further validate the surface biotinylation method and to confirm that DHPG induced a long-term facilitation of vesicular release at glutamatergic synapses, we conducted Syt1 antibody uptake assay. Control neurons or DHPG-treated ones were incubated with an antibody against the lumenal domain of Syt1, which could bind to Syt 1 exposed on the cell surface during vesicular release as described in previous studies (Malgaroli et al., 1995). The neurons were then colabeled with VGLUT1 to isolate the glutamatergic synapses and MAP2 to delineate the dendritic arbor. As shown in Figure 5, DHPG treatment increased both the puncta number and the fluorescence intensity of Syt 1 labeling in VGLUT1-posititve puncta, indicating an increase in the number of active glutamatergic presynaptic terminals and an enhanced 
A

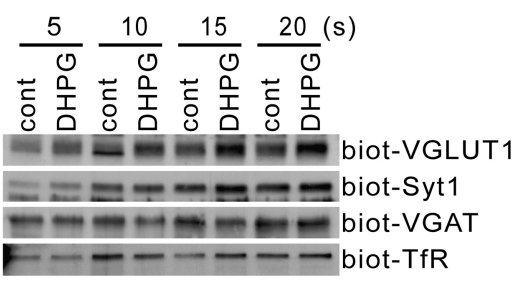

D

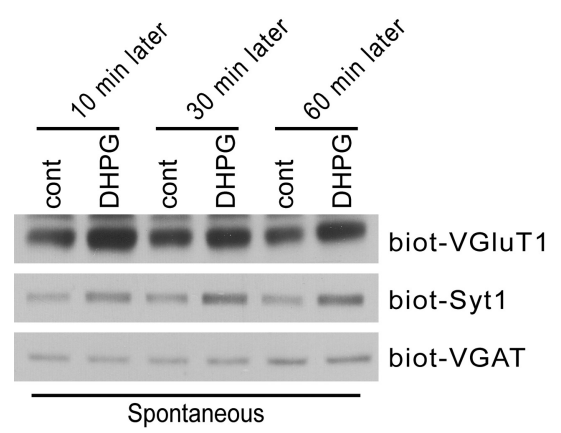

$\mathbf{F}$

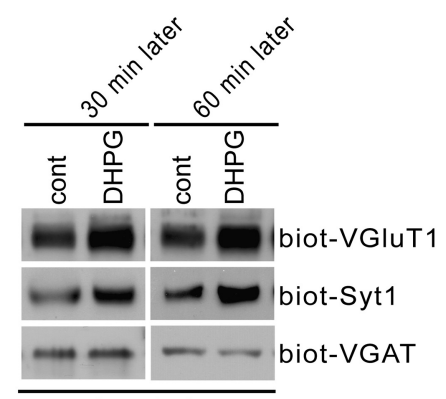

hypertonic

B

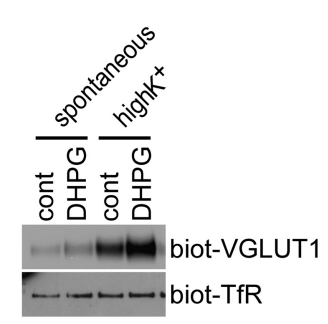

E

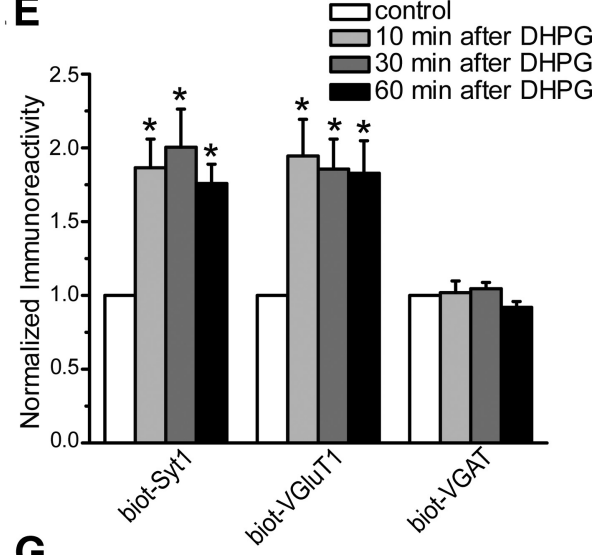

G

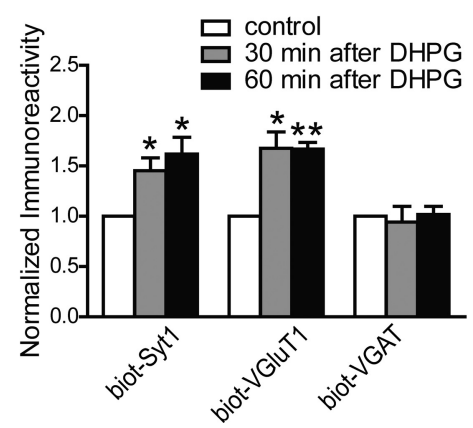

Figure 4. mGluR-LTD is associated with a long-term facilitation of glutamate release. $A, D H P G$ specifically increases spontaneous glutamate release from glutamatergic terminals. Neurons were treated with $100 \mu \mathrm{m}$ of DHPG for 5 min, followed by incubation in normal ECS for 45 min. Neurons were pretreated with $1 \mu \mathrm{m}$ of TTX before being switched into Sulfo-NHS-LC-Biotincontaining ECS for the indicated labeling periods. Representative blots $(\boldsymbol{A})$ showing that, after DHPG-induced LTD, there was a marked increase in biotinylation of vesicular proteins, including both VGLUT1 (biot-VGLUT1) and Syt1 (biot-Syt1) but not VGAT (biot-VGAT) or TfR (biot-TfR). B, C, DHPG increases both spontaneous and evoked vesicular glutamate release. Biotinylation was measured by incubating neurons for $30 \mathrm{~s}$ in Sulfo-NHS-LC-Biotin in normal ECS or high $\mathrm{K}^{+} 45$ min after treatment with DHPG. Representative blots $(\boldsymbol{B})$ and quantification ( $\boldsymbol{C}$ showing the effect of DHPG on VGLUT1 biotinylation under both spontaneous and evoked release conditions $\left({ }^{*} p<0.05,{ }^{* *} p<0.001\right.$, Student's $t$ test, $\left.n=5\right)$. $\boldsymbol{D}, \boldsymbol{E}$, Representative blots $(\boldsymbol{D})$ and quantification $(\boldsymbol{E})$ showing the time course of the effects induced by application of DHPG on spontaneous release. Neurons were treated with DHPG for $5 \mathrm{~min}$ and were subjected to biotinylation assay at 10,30, or $60 \mathrm{~min}$ after the removal of DHPG. Neurons were pretreated with TTX before biotinylation to monitor the spontaneous release of synaptic vesicles. Levels of both biotinylated Syt1 and VGLUT1 increased after DHPG treatment at all three time points ( ${ }^{*} p<0.05$, Student's $t$ test, $\left.n=4\right)$. F, G, DHPG treatment specifically affects the size of the readily releasable pool only in presynaptic glutamatergic terminals. Biotinylation labeling was conducted for $30 \mathrm{~s}$ in ECS containing $0.5 \mathrm{~m}$ of sucrose at 30 or 60 min after DHPG treatment, respectively. Representative blots $(\boldsymbol{F})$ and quantification $(\boldsymbol{G})$ showing that DHPG specifically and persistently enhances sucrose-evoked increase in VGLUT1 and Syt1 biotinylation but not VGAT biotinylation at both time points $\left({ }^{*} p<0.05,{ }^{* *} p<0.001\right.$, Student's $t$ test, $\left.n=4-6\right)$. cont, Control.

vesicular turnover at the terminals. Notably, the amplitude of changes induced by DHPG as revealed with Syt1 uptake assay was not as large as that observed with surface biotinylation assay. This is likely attributable to the large size of Syt1 antibody, which may limit its diffusion into the vesicles during fast release and recycle of vesicles. This further demonstrates the value of the surface biotinylation as a sensitive assay in monitoring synaptic release.
DHPG-induced presynaptic facilitation is downstream of AMPAR

\section{internalization}

The persistent increase in presynaptic release despite reduced $\mathrm{mEPSC}$ frequency and number of postsynaptic AMPARs during the expression of mGluR-LTD prompted us to examine whether the increase in presynaptic transmitter release reflected a compensatory presynaptic modification secondary to the reduced postsynaptic responsiveness resulting from enhanced endocytic removal of postsynaptic AMPARs. The surface biotinylation techniques allowed us to simultaneously measure DHPG-induced changes in presynaptic release, assessed by VGLUT1 biotinylation, and surface expression of AMPARs, assayed by AMPAR subunit GluAl biotinylation. We therefore examined the relationship between DHPG-induced presynaptic facilitation and postsynaptic depression and examined the effects of blocking alterations in AMPAR endocytosis on changes in presynaptic release using surface biotinylation in cultured hippocampal neurons. To block AMPAR endocytosis, we delivered the GluA $2_{3 \mathrm{Y}}$ peptide into neurons by premixing it with a peptide membrane penetrating carrier, peptide carrier (pep-1) (Morris et al., 2001). We showed previously that this method is able to efficiently deliver GluA2 $2_{3 \mathrm{Y}}$ peptide into cultured neurons and specifically block regulated endocytosis of AMPARs (Wang et al., 2004). Hippocampal neurons were incubated with ECS supplemented with or without the $\mathrm{GluA}_{3 \mathrm{Y}}$-pep-1 complex for $1 \mathrm{~h}$, followed by DHPG treatment (100 $\mu \mathrm{M} ; 5 \mathrm{~min})$. Thirty minutes later, neurons were incubated for $30 \mathrm{~s}$ with the biotinylation reagent, and the harvested and biotinylation levels of VGLUT1 and GluA1 were assayed with immunoblotting (Fig. $6 A, B)$. Consistent with increased AMPAR endocytosis during mGluR-LTD, DHPG significantly decreased surface expression of GluA1 (0.66 \pm 0.07-fold of control, $p<$ $0.01, t$ test, $n=5$ ). DHPG treatmentinduced decrease in surface AMPARs $(0.89 \pm 0.04$-fold of control, $p<0.01, t$ test, $n=5$ ) was abolished by GluA2 $2_{3 y}$ pretreatment $(p>0.05$ compared with control, $t$ test, $n=5$ ), consistent with the prevention of mGluR-LTD of mEPSCs by postsynaptic infusion of GluA2 $3 \mathrm{Y}$ (Fig. $3 F, G$ ). GluA2 $3 \mathrm{Y}$ alone failed to affect membrane expression of AMPARs (0.91 \pm 0.04-fold of control, $p>0.05, t$ test, $n=5)$. Membrane expression of TfR was not significantly changed by DHPG treatment $(1.11 \pm 0.14$-fold of control, $p>0.05, t$ test, $n=5)$ or GluA2 $3 \mathrm{YY}(1.00 \pm 0.11$-fold of control, $p>0.05$, $t$ test, $n=5$ ). These results indicate that DHPGinduced endocytosis of AMPARs is selectively blocked by GluA2 $_{3 \mathrm{Y}}$. 
As shown in Figure 6, $A$ and $B$, the level of VGLUT1 biotinylation measured in the same samples was increased by DHPG treatment $(1.74 \pm 0.15$-fold of control, $p<0.01$, $t$ test, $n=6$ ), in contrast to decreased level of surface AMPARs, and, as predicted, the increase was significantly attenuated by GluA2 $2_{3 Y}(1.26 \pm 0.14$-fold of DHPG-alone group, $p<0.01, t$ test; $p>0.05, t$ test compared with no DHPG control, $n=6$ ). GluA2 3 y alone did not significantly change VGLUT1 biotinylation $(0.85 \pm 0.10$-fold of control, $p>$ $0.05, t$ test, $n=6)$. VGAT biotinylation was not affected by either DHPG (1.05 \pm 0.15 -fold of control, $p>0.05$, $t$ test, $n=6$ ) or GluA2 3 Y $(0.93 \pm 0.15$-fold of control, $p>0.05, t$ test, $n=6)$. Because presynaptic changes after DHPG treatment were abolished by inhibiting internalization of postsynaptic AMPARs, our results indicate that presynaptic facilitation of synaptic release was, at least in part, a compensatory event downstream of postsynaptic internalization of AMPARs.

Because bath-applied GluA2 ${ }_{3 y}$ peptide complex could also be accumulated in presynaptic terminals, our findings could also be explained by an unknown direct effect of this complex on presynaptic release. However, this is unlikely because the complex did not affect VGAT biotinylation. To further rule out the potential effect of GluA2 $2_{3 Y}$ on presynaptic release, we tested the effect of the GluA2 $2_{3 Y}-$ pep- 1 complex on PMA-induced presynaptic facilitation. As shown in Figure 6, $C$ and D, whereas PMA significantly increased VGLUT1 biotinylation $(1.71 \pm 0.21$-fold of control, $p<0.05$, $t$ test, $n=4)$, GluA2 3 Y treatment did not affect either PMAinduced VGLUT1 biotinylation increase (1.59 \pm 0.20 -fold of PMA alone group, $p>0.05$, $t$ test, $p<0.05$, $t$ test compared with no PMA control, $n=4)$ or basal level of VGLUT1 biotinylation (0.90 \pm 0.04fold of control, $p>0.05$, $t$ test, $n=4$ ), suggesting that GluA2 $2_{3 \mathrm{Y}}$-pep-1 had no effect on either basal or PMA-stimulated presynaptic release. Moreover, neither PMA (1.05 \pm 0.26 -fold of control, $p>$ $0.05, t$ test, $n=4)$ nor GluA2 3 y peptide alone $(0.88 \pm 0.19$-fold of control, $p>0.05$, $t$ test, $n=4)$ significantly altered GluA1 surface expression. Together, our results suggest that GluA2 $2_{3 Y}$-pep-1 attenuates DHPG-induced presynaptic release as a result of its blockade of postsynaptic internalization of AMPARs.

\section{Discussion}

Assessing presynaptic transmitter release with surface biotinylation of vesicular transporters

Monitoring vesicular release of glutamate or GABA, the principal excitatory and inhibitory neurotransmitters in the brain, is tech-

A
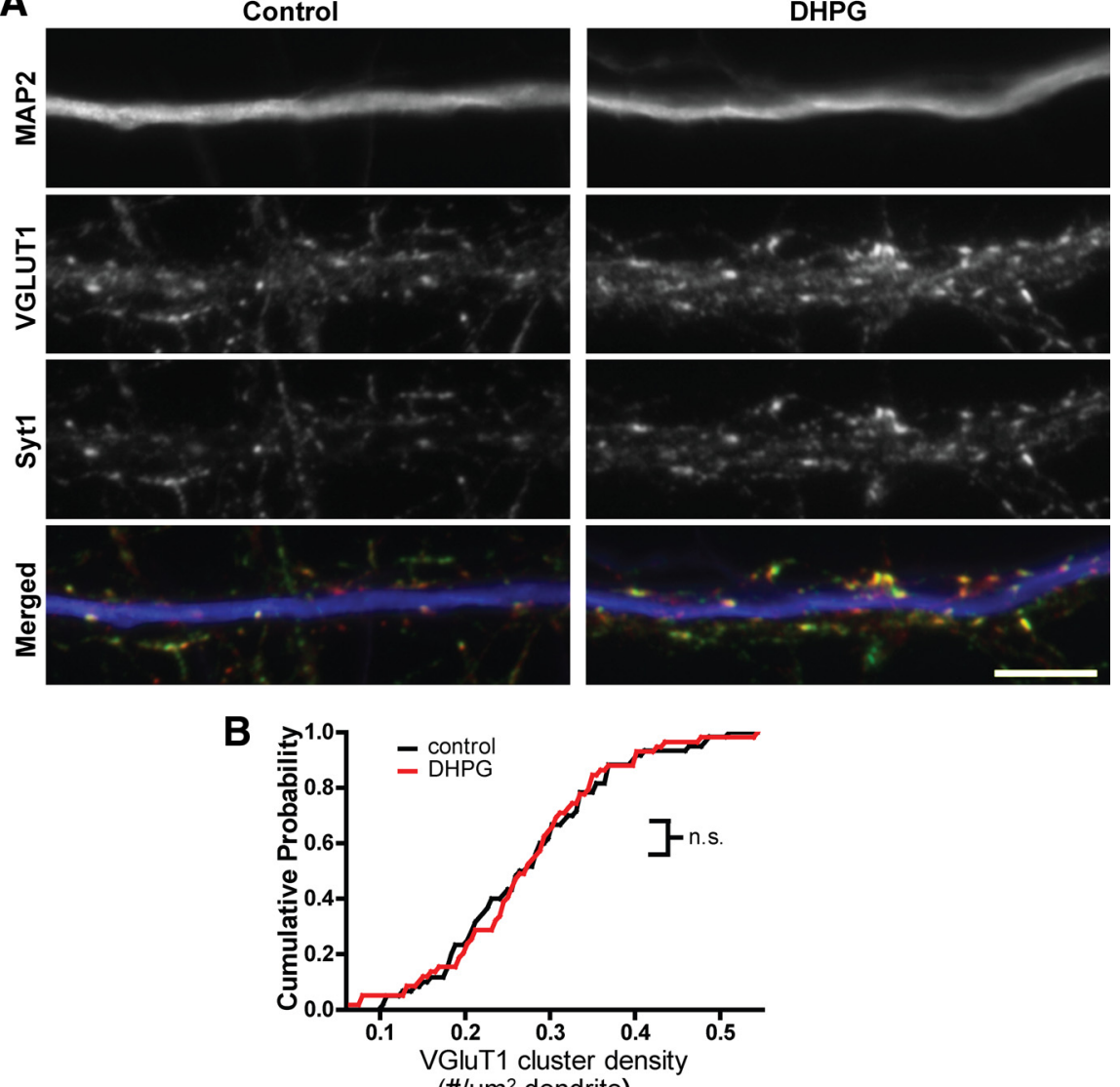

$\left(\# / \mu \mathrm{m}^{2}\right.$ dendrite)
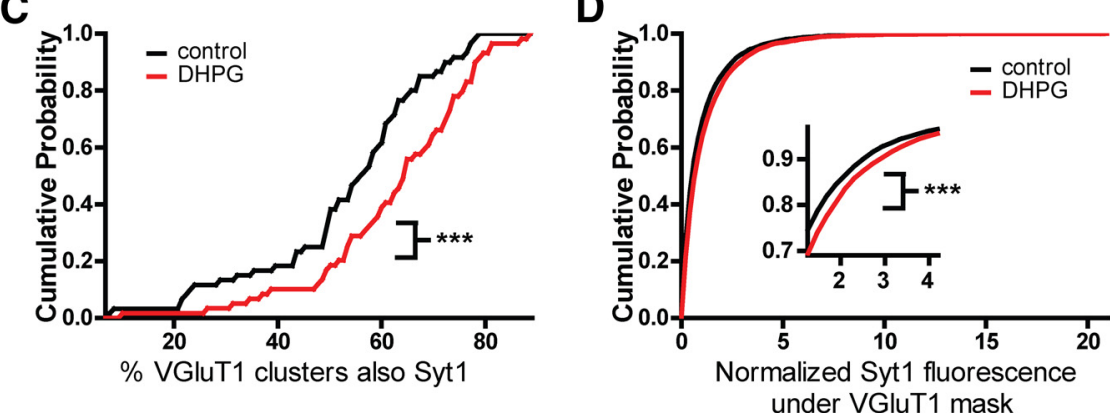

Figure 5. DHPG increased the number and recycling of active glutamatergic terminals. $\boldsymbol{A}$, Neurons were treated with DHPG (100 $\mu \mathrm{m})$ for $5 \mathrm{~min}$, followed by extensive washing and recovery for $30 \mathrm{~min}$. Subsequently, neurons were incubated with a rabbit antibody that recognizes the lumenal domain of Syt1 for $30 \mathrm{~min}$ at $37^{\circ} \mathrm{C}$ to label only those vesicles undergoing spontaneous release. Neurons were then fixed and immunostained for VGluT1, the primary rabbit Syt1 antibody, and MAP2 to label dendrites. Scale bar, $10 \mu \mathrm{m} . \boldsymbol{B}$, DHPG treatment did not alter the density of VGluT1-positive terminals ( $p>0.05$, Kolmogorov-Smirnov test, $n=3$ independent experiments). $\boldsymbol{C}$, The percentage of VGLUT1-positive terminals that were also positive for Syt1 immunoreactivity increased after DHPG treatment $\left({ }^{* * *} p<0.001\right.$, Kolmogorov-Smirnov test, $n=3$ independent experiments). D, The relative Syt1 immunoreactivity at individual VGLUT1-positive terminals was increased after DHPG treatment $\left({ }^{* *} p<0.001\right.$, Kolmogorov-Smirnov test, $n=3$ independent experiments).

nically challenging. Because of the active reuptake of these neurotransmitters by neurons and glial cells, measuring extracellular concentration of glutamate or GABA does not reflect the actual levels of release by presynaptic terminals. As touched on above, inferring presynaptic function by the analysis of postsynaptic currents is compromised by potential postsynaptic modifications. Imaging with FM dyes or antibodies lacks the ability to differentiate various types of synapses. Here, we provide evidence that the vesicular transporter biotinylation assay can be used to selectively monitor vesicular turnover at glutamatergic and GABAergic synapses, thereby providing a selective, direct, and 

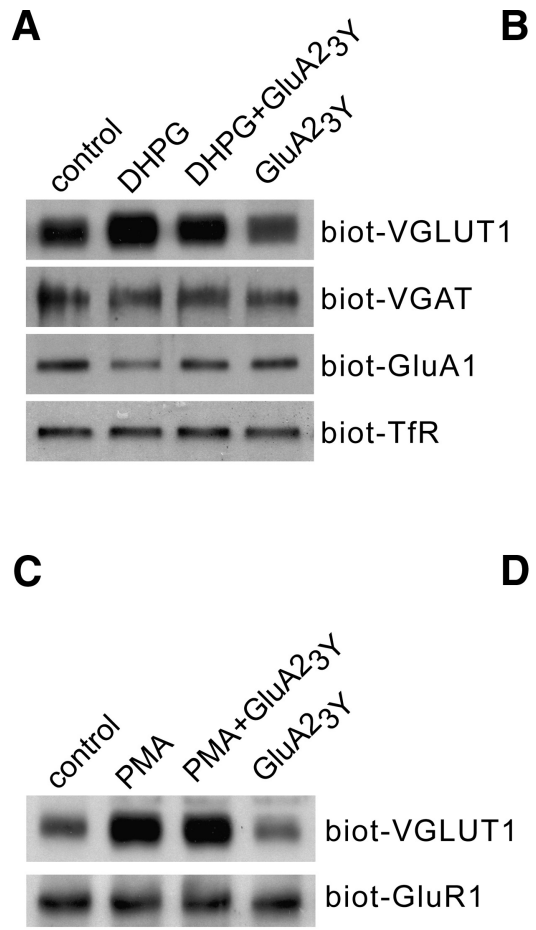

Figure 6. DHPG-induced facilitation of glutamate release during mGluR-LTD is downstream of AMPAR internalization. $\boldsymbol{A}, \boldsymbol{B}$, Inhibition of regulated AMPAR endocytosis prevents DHPG-induced increase in VGLUT1 biotinylation, as illustrated by representative blots in $\boldsymbol{A}$ and bar graph quantification in $\boldsymbol{B}$. GluA2 ${ }_{3 \mathrm{\gamma}}(1 \mu \mathrm{M})$ was first incubated with pep-1 membrane-permeant peptide carrier $(20 \mu \mathrm{M})$ for $30 \mathrm{~min}$ to form a membrane-permeant $\mathrm{GluA2}_{3 \mathrm{Y}}$ complex. Neurons were then pretreated with $\mathrm{GluA2}_{3 \mathrm{Y}}$ peptide complex for $1 \mathrm{~h}$, followed by DHPG treatment. The peptide complex was present throughout DHPG treatment and thereafter until the biotinylation measurement 45 min after DHPG treatment. This peptide blocked both DHPG-induced reduction in the biotinylation of surface AMPARs (biot-GluA1) and DHPG-induced increase in VGLUT1 biotinylation (biot-VGLUT1) without altering VGAT (biot-VGAT) and TfR biotinylation (biot-TfR) $\left({ }^{*} p<0.05\right.$, Student's $t$ test, $\left.n=5-6\right)$. C, D, The membrane-permeant GluA2 $_{3 Y}$ complex had no effect on basal surface AMPAR expression, nor did it affect basal and PMA-induced increase in presynaptic glutamate release, as illustrated in representative blots $(\boldsymbol{C})$ and bar graph quantification $(\boldsymbol{D})\left({ }^{*} p<0.05\right.$, Student's $t$ test, $\left.n=4\right)$. Neurons were treated with PMA in the presence or absence of $\mathrm{GluA2}_{3 \mathrm{\gamma}}$ peptide complex.

semiquantitative measurement of presynaptic glutamate or GABA release.

The biotinylation reagents used in the current study are small molecules with similar molecular weights and structures to that of FM dyes. It is safe to predict that these reagents assess vesicular turnover as efficiently as the dyes. A major advantage of the biotinylation assay is to allow the simultaneous detection of presynaptic modifications and postsynaptic alterations, such as the internalization of AMPARs. This unprecedented advantage allows the analysis of potential relationships between presynaptic and postsynaptic changes under different experimental conditions and, in particular, after the induction of various forms of synaptic plasticity.

Like other methods, this approach has its limitations. This technique measures the overall activity at all synapses in the culture without providing information on alterations in presynaptic activity at the single-synapse level. In addition, this technique measures synaptic vesicular turnover instead of the actual amount of released neurotransmitters, and as such, it can only be used as a semiquantitative method to indicate upregulation or downregulation but cannot be used to detect quantitative changes in transmitter release. Last, potential but perhaps insignificant surface membrane expression of vesicular proteins may reduce the accuracy of using vesicular protein labeling to estimate presynaptic release. Despite these shortcomings, this method (when combined with currently available techniques) is a valuable approach to provide new insights into modifications and underlying mechanisms of presynaptic release.

\section{Expression mechanism of DHPG-induced LTD}

DHPG-induced LTD was selected in the current study for several reasons. First, mGluR-LTD can be easily and reliably induced in both hippocampal cultures and slices (Fitzjohn et al., 2001; Snyder et al., 2001). Second, available findings suggest the existence of both presynaptic and postsynaptic modifications in this form of plastic change. Evidence supporting a presynaptic expression mechanism includes reduced mEPSC frequency and increased failure rate and paired-pulse facilitation of evoked excitatory postsynaptic responses (Fitzjohn et al., 2001). In addition, mGluR-LTD has also been attributed to a postsynaptic expression mechanism manifested as increased internalization of postsynaptic AMPARs (Snyder et al., 2001; Huang et al., 2004; Moult et al., 2006). The biotinylation assay allows simultaneous monitoring of both presynaptic and postsynaptic activities, providing an unprecedented opportunity to reevaluate the contribution of presynaptic modifications and to analyze potential relationships between presynaptic and postsynaptic modifications in mGluR-LTD.

In contrast to previous reports and our prediction, we did not observe reduction in presynaptic release during the expression phase of mGluR-LTD. Instead, we observed a persistent increase in release. Although the association of mGluR-LTD with enhanced presynaptic release is unexpected, this result is consistent with previous studies using synaptosomes (Reid et al., 1999; Lonart and Südhof, 2000). The seemingly paradoxical observations may be reconciled by a postsynaptic "silencing" process in which postsynaptic AMPARs at certain synapses are completely removed. Because vesicular release at a typical central synapse is normally only one quantum at a time (Redman, 1990), increased VGLUT1 labeling may reflect an increase in the frequency of quanta releases. This increase may occur at synapses that just became "silent" after DHPG treatment or at synapses that were still active. The final outcome in electrophysiology recording would be determined by the balance between increased release at active synapses and the reduced number of active synapses. Our results indicate that the reduction in the number of active synapses dominates the outcome in DHPG-induced synaptic depression.

Our observations of reduced cell-surface AMPARs after DHPG treatment and blockade of DHPG-induced reduction of mEPSC frequency by postsynaptic application of GluA $2_{3 Y}$ favor a predominantly postsynaptic expression mechanism in this form of plasticity. The mechanisms by which internalization of AMPARs at postsynaptic sites induces presynaptic changes remain to be elucidated. AMPAR internalization might induce the 
release of some diffusible retrograde messengers, which could in turn potentiate glutamate release. Arachidonic acid and its metabolites (Feinmark et al., 2003) as well as nitric oxide (Stanton et al., 2003) are potential candidates. In addition, AMPAR internalization might regulate presynaptic function by modifying interactions between trans-synaptic interacting molecules, such as neuroligin-neurexin (Futai et al., 2007), EphrinB-EphB (Grunwald et al., 2004), NCAM (Bozdagi et al., 2000), and integrins (Chavis and Westbrook, 2001).

Our results suggested the existence of functional coordination between presynaptic and postsynaptic components during the expression of mGluR-LTD. Such coordination between presynaptic and postsynaptic mechanisms has drawn increasing attention. Homeostatic interactions between presynaptic release and postsynaptic receptor function have been revealed after prolonged (hours or days) blockade of either presynaptic or postsynaptic activities (Turrigiano et al., 1998; Burrone et al., 2002; Thiagarajan et al., 2005; Aoto et al., 2008). Interestingly, it was reported recently that some fast retrograde mechanisms could increase presynaptic activity as a result of removal of the blockade of AMPAR (Lindskog et al., 2010). In our study, we showed a rapid homeostatic relationship between presynaptic and postsynaptic sites during the expression of mGluR-LTD, indicating that a mechanism in the opposite direction may also operate at synapses.

A potential physiological significance of increased presynaptic release during the expression of mGluR-LTD may be a compensatory/homeostatic mechanism to counteract the reduced synaptic efficacy resulting from endocytotic removal of AMPARs. Several mechanisms could account for such a compensatory homeostasis. First, because it is unlikely that postsynaptic AMPARs are saturated by presynaptically released glutamate under most conditions, the compensatory increase in presynaptic release might increase synaptic transmission by activation of more postsynaptic AMPARs. Second, increased presynaptic release might also result in a compensatory increase in synaptic transmission by activating other types of glutamate receptors, such as NMDA receptors and mGluRs, which, unlike AMPARs, may not be downregulated during mGluR-LTD. Finally, enhanced synaptic release may also increase synaptic transmission by increasing the formation of new synapses. If depressed synapses are destined to be eliminated as suggested previously (Kamikubo et al. 2006), then the facilitated presynaptic function could serve as a signaling mechanism for neighboring presynaptic boutons to attract postsynaptic partners to form new synaptic contacts.

mGluR-LTD is one of the best-characterized forms of synaptic plasticity (Waung et al., 2008; Lüscher and Huber, 2010). It has not only been implicated in various forms of learning and memory but has also been shown to have critical roles in the pathogenesis of a number of brain disorders, including drug addiction and fragile $\mathrm{X}$ syndrome. Therefore, understanding the induction and expression mechanisms underlying mGluR-LTD is of both physiological and pathological significance. Our discovery of an unexpected compensatory increase in presynaptic vesicular release in response to increased endocytosis of postsynaptic receptors during the expression of mGluR-LTD may open new avenues for studying mechanisms underlying presynaptic and postsynaptic regulation during this form of synaptic plasticity. Because increased endocytosis of AMPARs appears to represent a common mechanism for the expression of various forms of LTD in many brain areas (Collingridge et al., 2010), it would be interesting to know whether a similar compensatory increase in presynaptic release is also present in other forms of synaptic plasticity.

\section{References}

Aoto J, Nam CI, Poon MM, Ting P, Chen L (2008) Synaptic signaling by all-trans retinoic acid in homeostatic synaptic plasticity. Neuron 60:308320. CrossRef Medline

Aravanis AM, Pyle JL, Tsien RW (2003) Single synaptic vesicles fusing transiently and successively without loss of identity. Nature 423:643-647. CrossRef Medline

Bozdagi O, Shan W, Tanaka H, Benson DL, Huntley GW (2000) Increasing numbers of synaptic puncta during late-phase LTP: N-cadherin is synthesized, recruited to synaptic sites, and required for potentiation. Neuron 28:245-259. CrossRef Medline

Burrone J, O’Byrne M, Murthy VN (2002) Multiple forms of synaptic plasticity triggered by selective suppression of activity in individual neurons. Nature 420:414-418. CrossRef Medline

Chavis P, Westbrook G (2001) Integrins mediate functional pre- and postsynaptic maturation at a hippocampal synapse. Nature 411:317-321. CrossRef Medline

Collingridge GL, Isaac JT, Wang YT (2004) Receptor trafficking and synaptic plasticity. Nat Rev Neurosci 5:952-962. CrossRef Medline

Collingridge GL, Peineau S, Howland JG, Wang YT (2010) Long-term depression in the CNS. Nat Rev Neurosci 11:459-473. CrossRef Medline

Feinmark SJ, Begum R, Tsvetkov E, Goussakov I, Funk CD, Siegelbaum SA, Bolshakov VY (2003) 12-Lipoxygenase metabolites of arachidonic acid mediate metabotropic glutamate receptor-dependent long-term depression at hippocampal CA3-CA1 synapses. J Neurosci 23:11427-11435. Medline

Fitzjohn SM, Palmer MJ, May JE, Neeson A, Morris SA, Collingridge GL (2001) A characterisation of long-term depression induced by metabotropic glutamate receptor activation in the rat hippocampus in vitro. J Physiol 537:421-430. CrossRef Medline

Fremeau RT Jr, Troyer MD, Pahner I, Nygaard GO, Tran CH, Reimer RJ, Bellocchio EE, Fortin D, Storm-Mathisen J, Edwards RH (2001) The expression of vesicular glutamate transporters defines two classes of excitatory synapse. Neuron 31:247-260. CrossRef Medline

Futai K, Kim MJ, Hashikawa T, Scheiffele P, Sheng M, Hayashi Y (2007) Retrograde modulation of presynaptic release probability through signaling mediated by PSD-95-neuroligin. Nat Neurosci 10:186-195. CrossRef Medline

Grunwald IC, Korte M, Adelmann G, Plueck A, Kullander K, Adams RH, Frotscher M, Bonhoeffer T, Klein R (2004) Hippocampal plasticity requires postsynaptic ephrinBs. Nat Neurosci 7:33-40. CrossRef Medline

Heine M, Groc L, Frischknecht R, Béique JC, Lounis B, Rumbaugh G, Huganir RL, Cognet L, Choquet D (2008) Surface mobility of postsynaptic AMPARs tunes synaptic transmission. Science 320:201-205. CrossRef Medline

Hires SA, Zhu Y, Tsien RY (2008) Optical measurement of synaptic glutamate spillover and reuptake by linker optimized glutamate-sensitive fluorescent reporters. Proc Natl Acad Sci U S A 105:4411-4416. CrossRef Medline

Hsieh H, Boehm J, Sato C, Iwatsubo T, Tomita T, Sisodia S, Malinow R (2006) AMPAR removal underlies Abeta-induced synaptic depression and dendritic spine loss. Neuron 52:831-843. CrossRef Medline

Huang CC, You JL, Wu MY, Hsu KS (2004) Rap1-induced p38 mitogenactivated protein kinase activation facilitates AMPA receptor trafficking via the GDI. Rab5 complex. Potential role in (S)-3,5-dihydroxyphenylglyceneinduced long term depression. J Biol Chem 279:12286-12292. CrossRef Medline

Jeong HJ, Jang IS, Nabekura J, Akaike N (2003) Adenosine A1 receptormediated presynaptic inhibition of GABAergic transmission in immature rat hippocampal CA1 neurons. J Neurophysiol 89:1214-1222. CrossRef Medline

Kamikubo Y, Egashira Y, Tanaka T, Shinoda Y, Tominaga-Yoshino K, Ogura A (2006) Long-lasting synaptic loss after repeated induction of LTD: independence to the means of LTD induction. Eur J Neurosci 24:16061616. CrossRef Medline

Lindskog M, Li L, Groth RD, Poburko D, Thiagarajan TC, Han X, Tsien RW (2010) Postsynaptic GluA1 enables acute retrograde enhancement of presynaptic function to coordinate adaptation to synaptic inactivity. Proc Natl Acad Sci U S A 107:21806-21811. CrossRef Medline 
Lonart G, Südhof TC (2000) Assembly of SNARE core complexes prior to neurotransmitter release sets the readily releasable pool of synaptic vesicles. J Biol Chem 275:27703-27707. CrossRef Medline

Looger LL, Griesbeck O (2012) Genetically encoded neural activity indicators. Curr Opin Neurobiol 22:18-23. CrossRef Medline

Lüscher C, Huber KM (2010) Group 1 mGluR-dependent synaptic longterm depression: mechanisms and implications for circuitry and disease. Neuron 65:445-459. CrossRef Medline

Ma L, Zablow L, Kandel ER, Siegelbaum SA (1999) Cyclic AMP induces functional presynaptic boutons in hippocampal CA3-CA1 neuronal cultures. Nat Neurosci 2:24-30. CrossRef Medline

Malgaroli A, Ting AE, Wendland B, Bergamaschi A, Villa A, Tsien RW, Scheller RH (1995) Presynaptic component of long-term potentiation visualized at individual hippocampal synapses. Science 268:1624-1628. CrossRef Medline

Malinow R, Malenka RC (2002) AMPA receptor trafficking and synaptic plasticity. Annu Rev Neurosci 25:103-126. CrossRef Medline

Manzoni OJ, Manabe T, Nicoll RA (1994) Release of adenosine by activation of NMDA receptors in the hippocampus. Science 265:2098-2101. CrossRef Medline

McIntire SL, Reimer RJ, Schuske K, Edwards RH, Jorgensen EM (1997) Identification and characterization of the vesicular GABA transporter. Nature 389:870-876. CrossRef Medline

Morris MC, Depollier J, Mery J, Heitz F, Divita G (2001) A peptide carrier for the delivery of biologically active proteins into mammalian cells. Nat Biotechnol 19:1173-1176. CrossRef Medline

Moult PR, Gladding CM, Sanderson TM, Fitzjohn SM, Bashir ZI, Molnar E, Collingridge GL (2006) Tyrosine phosphatases regulate AMPA receptor trafficking during metabotropic glutamate receptor-mediated long-term depression. J Neurosci 26:2544-2554. CrossRef Medline

Murthy VN, Stevens CF (1999) Reversal of synaptic vesicle docking at central synapses. Nat Neurosci 2:503-507. CrossRef Medline

Padamsey Z, Jeans A (2012) Imaging synaptic vesicles using VGLUT1Venus knock-in mice: insights into the dynamic nature of intersynaptic vesicle exchange. J Neurosci 32:3284-3286. CrossRef Medline

Redman S (1990) Quantal analysis of synaptic potentials in neurons of the central nervous system. Physiol Rev 70:165-198. Medline

Reid ME, Toms NJ, Bedingfield JS, Roberts PJ (1999) Group I mGlu receptors potentiate synaptosomal $\left[{ }^{3} \mathrm{H}\right]$ glutamate release independently of exogenously applied arachidonic acid. Neuropharmacology 38:477-485. CrossRef Medline

Rhee JS, Betz A, Pyott S, Reim K, Varoqueaux F, Augustin I, Hesse D, Südhof TC, Takahashi M, Rosenmund C, Brose N (2002) Beta phorbol esterand diacylglycerol-induced augmentation of transmitter release is mediated by Munc13s and not by PKCs. Cell 108:121-133. CrossRef Medline
Rosenmund C, Stevens CF (1996) Definition of the readily releasable pool of vesicles at hippocampal synapses. Neuron 16:1197-1207. CrossRef Medline

Silverman MA, Kaech S, Jareb M, Burack MA, Vogt L, Sonderegger P, Banker G (2001) Sorting and directed transport of membrane proteins during development of hippocampal neurons in culture. Proc Natl Acad Sci U S A 98:7051-7057. CrossRef Medline

Snyder EM, Philpot BD, Huber KM, Dong X, Fallon JR, Bear MF (2001) Internalization of ionotropic glutamate receptors in response to mGluR activation. Nat Neurosci 4:1079-1085. CrossRef Medline

Stanton PK, Winterer J, Bailey CP, Kyrozis A, Raginov I, Laube G, Veh RW, Nguyen CQ, Müller W (2003) Long-term depression of presynaptic release from the readily releasable vesicle pool induced by NMDA receptordependent retrograde nitric oxide. J Neurosci 23:5936-5944. Medline

Takamori S, Rhee JS, Rosenmund C, Jahn R (2000) Identification of a vesicular glutamate transporter that defines a glutamatergic phenotype in neurons. Nature 407:189-194. CrossRef Medline

Thiagarajan TC, Lindskog M, Tsien RW (2005) Adaptation to synaptic inactivity in hippocampal neurons. Neuron 47:725-737. CrossRef Medline

Turrigiano GG, Leslie KR, Desai NS, Rutherford LC, Nelson SB (1998) Activity-dependent scaling of quantal amplitude in neocortical neurons. Nature 391:892-896. CrossRef Medline

Voglmaier SM, Kam K, Yang H, Fortin DL, Hua Z, Nicoll RA, Edwards RH (2006) Distinct endocytic pathways control the rate and extent of synaptic vesicle protein recycling. Neuron 51:71-84. CrossRef Medline

Wang Y, Ju W, Liu L, Fam S, D'Souza S, Taghibiglou C, Salter M, Wang YT (2004) alpha-Amino-3-hydroxy-5-methylisoxazole-4-propionic acid subtype glutamate receptor (AMPAR) endocytosis is essential for $N$-methyl-Daspartate-induced neuronal apoptosis. J Biol Chem 279:41267-41270. CrossRef Medline

Waung MW, Pfeiffer BE, Nosyreva ED, Ronesi JA, Huber KM (2008) Rapid translation of Arc/Arg3.1 selectively mediates mGluR-dependent LTD through persistent increases in AMPAR endocytosis rate. Neuron 59:84-97. CrossRef Medline

Xiao MY, Zhou Q, Nicoll RA (2001) Metabotropic glutamate receptor activation causes a rapid redistribution of AMPA receptors. Neuropharmacology 41:664-671. CrossRef Medline

Zakharenko SS, Zablow L, Siegelbaum SA (2002) Altered presynaptic vesicle release and cycling during mGluR-dependent LTD. Neuron 35:1099-1110. CrossRef Medline

Zhang XL, Zhou ZY, Winterer J, Müller W, Stanton PK (2006) NMDAdependent, but not group I metabotropic glutamate receptor-dependent, long-term depression at Schaffer collateral-CA1 synapses is associated with long-term reduction of release from the rapidly recycling presynaptic vesicle pool. J Neurosci 26:10270-10280. CrossRef Medline 